УДК 338.012

DOI 10.18413/2687-0932-2020-47-2-308-316

\title{
ВЫЯВЛЕНИЕ И КЛАССИФИКАЦИЯ ПОКАЗАТЕЛЕЙ ЭНЕРГЕТИЧЕСКОЙ ЭФФЕКТИВНОСТИ ПРЕДПРИЯТИЯ КАК ОСНОВА РАЦИОНАЛЬНОГО РАСХОДОВАНИЯ ТОПЛИВНО-ЭНЕРГЕТИЧЕСКИХ РЕСУРСОВ
}

\section{IDENTIFICATION AND CLASSIFICATION OF INDICATORS OF ENERGY EFFICIENCY OF THE ENTERPRISE AS THE BASIS OF RATIONAL CONSUMPTION OF FUEL AND ENERGY RESOURCES}

\author{
И.А. Киршина \\ I.A. Kirshina \\ ФГАОУ ВО «УрФУ имени первого Президента России Б.Н. Ельцина» \\ Россия, 620002, Уральский федеральный округ, Свердловская область, Екатеринбург, ул. Мира, 19 \\ Ural Federal University named after the First President of Russia B.N. Yeltsin \\ 19 Mira St., Yekaterinburg, Sverdlovsk Region, Ural Federal District, 620002, Russia \\ E-mail: i.kirshina@yandex.ru
}

\begin{abstract}
Аннотация
Автором выявлена необходимость создания системной оценки и систематизации факторов энергоэффективности, которые оказывают влияние на расходование топливно-энергических ресурсов промышленных предприятий. Проведен анализ работ отечественных ученых и специалистов в области определения и классификации факторов энергоэффективности промышленных предприятий. Анализ показал, что в данных исследованиях отображен неполный набор факторов и условий, влияющих на энергоэффективность использования топливно-энергетических ресурсов в промышленности Российской Федерации. Рассмотрены и сгруппированы факторы и условия, влияющие на энергоэффективность потребления природного газа промышленными предприятиями. Систематизация факторов энергоэффективности осуществлялась на примере предприятий металлургии, машиностроения и электроэнергетики на основе пяти наиболее значимых групп факторов: производственные, технологические, организационные, социально-экономические, климатические. Определены взаимосвязи компонентов классификации факторов, и выявлены ключевые предпосылки повышения энергоэффективности и повышения энергетической эффективности промышленных предприятий.
\end{abstract}

\begin{abstract}
The author revealed the need to create a systematic assessment of the systematization of energy efficiency factors that affect the consumption of fuel and energy resources of industrial enterprises. The analysis of research of domestic scientists and specialists in the field of determination and classification of factors of energy efficiency of industrial enterprises. The analysis showed that in these works an incomplete list of factors affecting the energy efficiency of the use of fuel and energy resources in the industry of the Russian Federation is presented. Factors and conditions affecting the energy efficiency of natural gas consumption by industrial enterprises are considered and grouped. The systematization of energy efficiency factors was carried out on the example of metallurgy, engineering and electric power enterprises on the basis of the five most significant groups of factors: production, technological, organizational, socio-economic, and climate. The interconnections of the components of the classification of factors are determined, and the key prerequisites for improving energy efficiency and improving energy efficiency of industrial enterprises are identified.
\end{abstract}


Ключевые слова: энергосбережение, энергоэффективность, факторы энергоэффективности, природный газ, промышленные предприятия.

Keywords: energy saving, energy efficiency, energy efficiency factors, natural gas, industrial enterprises.

\section{Введение}

На сегодняшний день трудно недооценивать значимость проблемы эффективного использования топливно-энергетических ресурсов (далее - ТЭР) различными экономическими агентами. Большинство стран осознают необходимость изменения своих подходов к повышению эффективности использования ТЭР. Вопросы энергетической безопасности, социально-экономические последствия повышения стоимости энергетических ресурсов, а также распространение информации о глобальном изменении климата способствовали тому, что много стран стали уделять большее значение разработке стратегий в области энергосбережения и повышения энергетической эффективности [Киршина, Федорова, 2020, p. 77; Башмаков, 2014; Башмаков, 2018].

Поиск решения этой задачи крайне значим для Российской Федерации, где удельное потребление ТЭР на производство единицы продукции в несколько раз превосходят аналогичные показатели в странах Западной Европы, Канады, США и Японии [Башмаков, 2012; Показатели энергоэффективности...].

Во исполнение Указа Президента Российской Федерации от 4 июня 2008 г. № 889 «О некоторых мерах по повышению энергетической и экологической эффективности российской экономики» перед Правительством Российской Федерации была поставлена задача снижения энергоемкости ВВП к 2020 г. не менее, чем на 40 \% по сравнению с показателем 2007 г. [Государственный доклад...].

Согласно данным Министерства экономического развития России, отраженным в государственном докладе о состоянии энергосбережения и повышении энергетической эффективности, энергоемкость ВВП по итогам 2018 г. снизилась на 12 \% по отношению к 2007 г., причем за последние четыре года она не претерпела изменений [Башмаков, 2016; Прогноз развития...].

\section{Основные результаты исследования}

В соответствии с Федеральным законом № 261-Ф3 от 23.11.2009 года «Об энергосбережении и о повышении энергетической эффективности» под энергетической эффективностью понимаются показатели, которые определяются непосредственно отношением полезного эффекта от использования ТЭР к затратам ТЭР, произведенным в целях производства продукции или выполнения производственного процесса [Федеральный закон...].

Формирование основных принципов рациональной политики в части энергосбережения предполагает наличие совокупности качественных, своевременных и сравнимых показателей, которые выходят далеко за пределы топливно-энергетических балансов и отражают специфические характеристики экономической деятельности и ресурсов, имеющихся в каждой стране [Туликов, Туликова, 2012].

Создание механизма управления энергопотреблением промышленного предприятия предполагает систематизацию факторов повышения эффективности энергопотребления [Bonilla-Camposab, Nieto, 2020]. В классическом понимании факторы энергоэффективности представляют собой некоторые причины, воздействующие на удельное потребление энергоресурсов, и совокупность показателей, способствующих их экономному использованию [Киршина, Федорова, 2020; Марченко, Белова, 2019].

Компоненты и их параметры, оказывающие влияние на потребления ТЭР, могут быть схожими и существенно различаться между собой. Это зависит от региона, отрасли промышленности, типа предприятия, вида потребляемых ТЭР и др. факторов. 
Поэтому к первоначальному этапу анализа воздействия различных факторов на уровень эффективности использования энергоресурсов предприятия относится то, как изучалась данная проблема специалистами в данной сфере. Данный подход поможет определить взаимосвязь факторов энергоэффективности и установить степень их влияния на потребление ТЭР [Дзюба, Соловьева, 2018; König, 2020].

Рассматриваемая область исследования связана с достаточно сложным и обширным объемом знаний, в становление и развитие которого внесли заметный вклад многие отечественные специалисты.

Результаты исследования проблем энергосбережения и повышения энергетической эффективности в различных отраслях народного хозяйства описаны в трудах И.А. Башмакова и ряда иностранных авторов [Башмаков, 2018; The impact...].

В.А. Кокшаровым в своих исследованиях проведена работа по выявлению взаимосвязи и систематизации факторов энергоэффективности предприятий с целью определения соответствующих показателей при формировании и реализации программ по экономии энергоресурсов в будущем. Большое значение представляет собой предложенная автором таблица взаимосвязи факторов энергоэффективности для последующего построения корреляционно-регрессионных моделей прогнозирования потребления ТЭР предприятиями [Кокшаров, 2016].

Некоторые специалисты рассматривают факторы энергоэффективности потребления энергоресурсов с точки зрения национальной экономики, зональных и региональных особенностей, модернизации и развития экономики, конкурентоспособности товаров и услуг [Киршина, Федорова, 2020; Лебедев, Летягина, 2014].

Л.А. Морулева в своей работе [Морулева, 2015] выделяет ряд факторов, оказывающих влияние на энергоэффективность экономики. К таким факторам относятся величина и структура валового внутреннего продукта, величина физического и морального износа технологического оборудования, состояние нормативно-правовой базы в сфере энергосбережения и повышения энергетической эффективности. Также к значимым факторам автор относит потенциал энергосбережения в различных секторах экономики, использование различных инструментов и методических подходов в области энергосбережения, уровень осведомленности и вовлеченности персонала в процесс энергосбережения и эффективного использования ТЭР.

Сформированная Л.А. Головановой и А.А. Московцевой группировка показателей энергоэффективности подразумевает два уровня: факторы первого и второго порядков. На первом уровне осуществляется внешнее и внутреннее влияние на энергоэффективность использования ТЭР. На втором уровне внешние факторы подразделяются на прямые и косвенные. Внешние прямые факторы включают в себя энергетические затраты при создании промышленной продукции и меры отраслевого управления энергосбережением. Внешние косвенные факторы определяются политическими, экологическими и территориальными условиями [Киршина, Федорова, 2020].

В свою очередь, к внутренним факторам авторы относят условно объективные (энергосберегающие технологии, энерговооруженность персонала) и условно субъективные (источники финансирования, информация по энергосбережению) [Киршина, Федорова, 2020; Голованова, Московцева, 2014].

В работе А.П. Дзюбы и И.А. Соловьевой приведены различные типы факторов, влияющие на параметры графиков спроса на природный газ промышленными предприятиями. Авторами статьи рассмотрены факторы, оказывающие воздействие на характеристики графиков потребления природного газа промышленными предприятиями [Дзюба, Соловьева, 2018]. Предложенная систематизация факторов имеет серьезный недостаток, так как не учитывает очень важную группу организационных факторов (что является также недостатком целого ряда существующих подходов к систематизации факторов), и является принципиальным моментом в систематизации факторов энергоэффективности потребления природного газа промышленными предприятиями.

Анализ вышеперечисленных научных точек зрения касательно процессов энергосбережения позволяет установить, что в данных исследованиях представлен 
ограниченный перечень факторов, влияющих на энергоэффективность использования ТЭР в промышленности. В частности, четко не выделяются организационные факторы, которые, являясь интеграционными, обеспечивают соединение всех факторов в единый процесс и позволяют выходить на систему показателей для оценки степени достижения целей организации производства, что является необходимой основой стратегического управления потреблением природного газа [Huysmana, Sala, 2015].

Процесс управления потреблением природного газа промышленными предприятиями в современных условиях требует принципиально нового механизма повышения энергоэффективности. Для этого необходимо обозначить факторы, которые тем или иным способом оказывают влияние на величину потребления природного газа. [Киршина, Федорова, 2020; Ишков, Цыбульский и др., 2013]

Прежде чем снижать потребление газа промышленным предприятием, необходимо определить, от чего оно зависит и какого характера эта зависимость. Поскольку крупнейшими потребителями природного газа среди отраслей экономики России являются металлургия, электроэнергетика и машиностроение, рассмотрим систематизацию факторов энергоэффективности на их примере. В металлургии и машиностроении природный газ широко используют при выплавке чугуна и для нагрева прокатных, кузнечных и плавильных печей, в электроэнергетике - для генерации электрической энергии.

На рис. 1 представлена классификация факторов энергоэффективности в различных отраслях промышленности России.

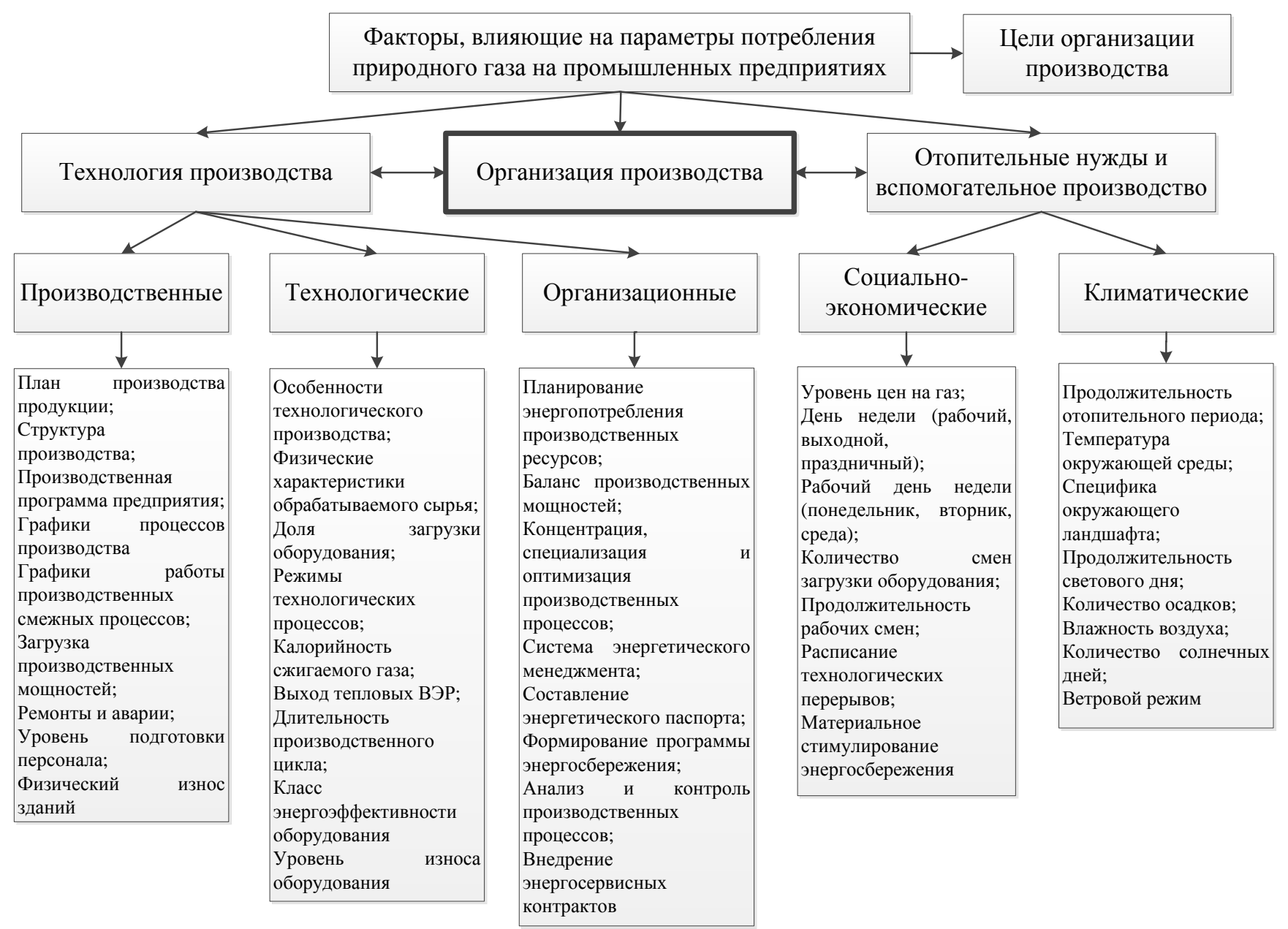

Рис. 1. Систематизация факторов, влияющих на достижение целей организации при потреблении природного газа на промышленных предприятиях

Fig. 1. Systematization of factors affecting the achievement of the organization's goals when consuming natural gas in industrial enterprises

Источник: составлено автором 
Систематизация факторов осуществлялась посредством их группировки на 5 типов:

- производственные;

- технологические;

- организационные;

- социально-экономические;

- климатические.

Производственные, технологические и организационные факторы, в свою очередь, относятся к технологии производства. На эти факторы предприятие сильно воздействовать не может, однако обязано учитывать и использовать их в своей деятельности. Организационные факторы позволяют соединить все факторы в единый процесс для эффективной оценки степени достижения целей организации производства, что является необходимой основой стратегического управления потреблением природного газа.

Их наличие является определяющим моментом при систематизации факторов энергоэффективности потребления природного газа промышленными предприятиями.

Социально-экономические и климатические факторы энергоэффективности представляют собой группы «отопительные нужды и вспомогательное производство». Предприятие может активно воздействовать на них и пытаться снизить влияние этих факторов до определённого уровня.

Важным аспектом изучения проблемы эффективного расходования ТЭР на предприятии является оценка взаимосвязи между величиной потребления топлива промышленными предприятиями и различными факторами. В работе [Киршина, Федорова, 2020] авторами была рассмотрена степень влияния различных факторов энергоэффективности на расход природного газа в металлургии, электроэнергетике и машиностроении (табл. 1) [Киршина, Федорова, 2020].

Определение степени воздействия факторов на потребление ТЭР способствует грамотному формированию энергосберегающей стратегии предприятия.

Таблица 1

Table1

Влияние факторов энергоэффективности на организацию производства промышленного предприятия

The influence of energy efficiency factors on the organization of production of an industrial enterprise

\begin{tabular}{|c|l|l|l|}
\hline \multirow{2}{*}{$\begin{array}{c}\text { Степень } \\
\text { влияния } \\
\text { фактора }\end{array}$} & \multicolumn{3}{|c|}{ Отрасль экономики } \\
\cline { 2 - 4 } & \multicolumn{1}{|c|}{ Металлургия } & \multicolumn{1}{|c|}{ Электроэнергетика } & \multicolumn{1}{|c|}{ Машиностроение } \\
\hline $\mathbf{1}$ & \multicolumn{1}{|c|}{$\mathbf{|}$} & \multicolumn{1}{|c|}{$\mathbf{4}$} \\
\hline Высокая & $\begin{array}{l}\text { План производства } \\
\text { продукции; } \\
\text { Загрузка } \\
\text { производственных } \\
\text { мощностей; } \\
\text { Особенности } \\
\text { технологического } \\
\text { производства; Класс } \\
\text { энергэффективности } \\
\text { оборудования; } \\
\text { Планирование } \\
\text { энергопотребления } \\
\text { производственных } \\
\text { ресурсов }\end{array}$ & $\begin{array}{l}\text { План производства } \\
\text { продукции; } \\
\text { Загрузка производственных } \\
\text { мощностей; } \\
\text { Особенности } \\
\text { технологического } \\
\text { производства; } \\
\text { Калорийность сжигаемого } \\
\text { газа; Класс } \\
\text { энергоэффективности } \\
\text { оборудования;Планирование } \\
\text { энергопотребления } \\
\text { плительность } \\
\text { производственного цикла; } \\
\text { Класс } \\
\text { энергоэффективности } \\
\text { оборудования; }\end{array}$ \\
\hline
\end{tabular}


Окончание табл. 1

\begin{tabular}{|c|c|c|c|}
\hline 1 & 2 & 3 & 4 \\
\hline Средняя & $\begin{array}{l}\text { Структура производства; } \\
\text { Производственная } \\
\text { программа предприятия; } \\
\text { Графики процессов } \\
\text { производства; } \\
\text { Графики работы } \\
\text { производственных } \\
\text { смежных процессов; } \\
\text { Физический износ зданий; } \\
\text { Физические } \\
\text { характеристики } \\
\text { обрабатываемого сырья; } \\
\text { Режимы технологических } \\
\text { процессов; Длительность } \\
\text { производственного цикла; } \\
\text { Концентрация, } \\
\text { специализация и } \\
\text { оптимизация } \\
\text { производственных } \\
\text { процессов; } \\
\text { Формирование программы } \\
\text { энергосбережения; } \\
\text { Анализ и контроль } \\
\text { производственных } \\
\text { процессов }\end{array}$ & $\begin{array}{l}\text { Структура производства } \\
\text { Производственная } \\
\text { программа предприятия } \\
\text { Графики процессов } \\
\text { производства } \\
\text { Графики работы } \\
\text { производственных смежных } \\
\text { процессов } \\
\text { Физический износ зданий; } \\
\text { Режимы технологических } \\
\text { процессов; } \\
\text { Формирование программы } \\
\text { энергосбережения; } \\
\text { Анализ и контроль } \\
\text { производственных } \\
\text { процессов }\end{array}$ & $\begin{array}{l}\text { Загрузка } \\
\text { производственных } \\
\text { мощностей } \\
\text { Физический износ зданий } \\
\text { Особенности } \\
\text { технологического } \\
\text { производства } \\
\text { Физические } \\
\text { характеристики } \\
\text { обрабатываемого сырья } \\
\text { Режимы технологических } \\
\text { процессов; Длительность } \\
\text { производственного цикла; } \\
\text { Планирование } \\
\text { энергопотребления } \\
\text { производственных } \\
\text { ресурсов; } \\
\text { Формирование программы } \\
\text { энергосбережения; } \\
\text { Анализ и контроль } \\
\text { производственных } \\
\text { процессов }\end{array}$ \\
\hline Низкая & $\begin{array}{l}\text { Уровень подготовки } \\
\text { персонала; } \\
\text { Доля загрузки } \\
\text { оборудования; } \\
\text { Калорийность сжигаемого } \\
\text { газа; } \\
\text { Выход тепловых ВЭР; } \\
\text { Уровень износа } \\
\text { оборудования; } \\
\text { Баланс производственных } \\
\text { мощностей; } \\
\text { Система энергетического } \\
\text { менеджмента; } \\
\text { Составление } \\
\text { энергетического паспорта; } \\
\text { Внедрение } \\
\text { энергосервисных } \\
\text { контрактов }\end{array}$ & $\begin{array}{l}\text { Уровень подготовки } \\
\text { персонала; } \\
\text { Физические характеристики } \\
\text { обрабатываемого сырья; } \\
\text { Доля загрузки } \\
\text { оборудования; } \\
\text { Выход тепловых ВЭР; } \\
\text { Уровень износа } \\
\text { оборудования; } \\
\text { Баланс производственных } \\
\text { мощностей; } \\
\text { Концентрация, } \\
\text { специализация и } \\
\text { оптимизация } \\
\text { производственных } \\
\text { процессов; } \\
\text { Система энергетического } \\
\text { менеджмента; } \\
\text { Составление } \\
\text { энергетического паспорта; } \\
\text { Внедрение энергосервисных } \\
\text { контрактов }\end{array}$ & $\begin{array}{l}\text { Структура производства; } \\
\text { Производственная } \\
\text { программа предприятия; } \\
\text { Графики процессов } \\
\text { производства; } \\
\text { Графики работы } \\
\text { производственных } \\
\text { смежных процессов; } \\
\text { Уровень подготовки } \\
\text { персонала; } \\
\text { Доля загрузки } \\
\text { оборудования; } \\
\text { Калорийность сжигаемого } \\
\text { газа; Выход тепловых ВЭР; } \\
\text { Уровень износа } \\
\text { оборудования; } \\
\text { Баланс производственных } \\
\text { мощностей; } \\
\text { Концентрация, } \\
\text { специализация и } \\
\text { оптимизация } \\
\text { производственных } \\
\text { процессов; } \\
\text { Система энергетического } \\
\text { менеджмента; } \\
\text { Составление } \\
\text { энергетического паспорта; } \\
\text { Внедрение } \\
\text { энергосервисных } \\
\text { контрактов }\end{array}$ \\
\hline
\end{tabular}

Источник: [Киршина, Федорова, 2020]. 


\section{Заключение}

За последние десять лет процесс энергосбережения в стране резко замедлился, энергоемкость ВВП Российской Федерации снизилась всего на 9\%, а отставание в организационном и технологическом плане от развитых стран в настоящее время по-прежнему не уменьшается. Структурные сдвиги на уровне ряда секторов экономики и другие факторы не способствовали снижению энергоемкости ВВП страны. Построение эффективной системы управления энергосбережением и повышением энергоэффективности является ключевым фактором успешного функционирования как промышленных предприятий, так и экономики страны в целом.

В работе проведен анализ основных подходов к систематизации и классификации факторов энергоэффективности потребления топливно-энергетических ресурсов. В рассмотренных подходах выявлено отсутствие группы организационных факторов. Данные факторы являются интеграционными и обеспечивают соединение всех рассматриваемых факторов в единый процесс, что является необходимой основой стратегического управления потреблением природного газа промышленными предприятиями.

Предложенная классификация факторов энергоэффективности среди промышленных предприятий позволяет определить взаимосвязь ключевых компонентов, обеспечивающих предпосылки для сбережения энергии на промышленных предприятиях. Данная типология определяет ключевые особенности формирования энергоэффективности потребления природного газа промышленными предприятиями в России.

\section{Список литературы}

1. Башмаков И.А. 2014. За счет чего снижается энергоемкость ВВП России. Энергосбережение, (№ 1): 12-18;

2. Башмаков И.А., Башмаков В.И. 2012. Политика повышения энергоэффективности России, Энергосбережение, (№ 4): 10-16;

3. Башмаков И.А. 2018. Что происходит с энергоемкостью ВВП России? Экологический вестник России, (№ 7):18-29;

4. Башмаков И.А. 2016. Энергопотребление регионов России. О реальной динамике и о качестве статистики. Энергосбережение, (№ 5):24-29;

5. Голованова Л.А., Московцева А.А. 2014. Факторы и условия энергоэффективности в промышленности. Вестник ТОГУ, № 3(34): 137-146;

6. Государственный доклад о состоянии энергосбережения и повышении энергетической эффективности в Российской Федерации URL:https://www.economy.gov.ru/material/file/d81b2 9821e3d3f5a8929c84d808de81d/energyefficiency2019.pdf (дата обращения 25 февраля 2020);

7. Дзюба А.П., Соловьева И.А. 2018. Краткосрочное прогнозирование параметров потребления природного газа как элемент ценозависимого управления энергозатратами на промышленных предприятиях. Вестник ВолГУ. Серия 3, Экономика. Экология. Т. 20 (№ 1):78-90;

8. Ишков А.Г., Цыбульский П.Г., Пыстина Н.Б. и др. 2013. Стратегия формирования методов управления энергосбережением в ОАО «Газпром». Вести газовой науки: охрана окружающей среды, энергосбережение и охрана труда в нефтегазовом комплексе: инновации, технологии, перспективы, № 2 (13):14-20;

9. Кокшаров В.А. 2016. Систематизация факторов энергоэффективности промышленного предприятия. Вестник Пермского университета. Серия: экономика, 1(28): 147-156;

10.Киршина И.А., Федорова С.Е. Систематизация факторов энергоэффективности потребления природного газа промышленными предприятиями. 2020. Проблемы экономики и управления нефтегазовым комплексом, № 4(184): 77-79.

11.Лебедев Ю.А., Летягина Е.Н. 2014. Регрессионный анализ энергопотребления в промышленных регионах. Вестник Нижегородского университета им. Н.И. Лобачевского. Серия: социальные науки, № 3(35): 29-32;

12.Марченко Е.М., Белова Т.Д. Анализ факторов, влияющих на энергоэффективность региона: управленческий аспект. URL: http://vestnik.uapa.ru/ru/issue/2015/04/15/ (дата обращения 12 января 2019); 
13.Морулева Л.А. 2015. Анализ факторов, оказывающий влияние на энергоэффективность экономики. Международный научно-исследовательский журнал, 6-3 (37): 75-77;

14.Показатели энергоэффективности: основы формирования политики. URL:https://altenergiya. ru/wp-content/uploads/books/common/pokazateli-energoeffektivnosti.pdf (дата обращения 12.01.2019);

15.Прогноз развития энергетики мира и России до 2040 года. URL:https://www.eriras. ru/files/prognoz-2040.pdf (дата обращения 25 февраля 2020);

16.Туликов А.В., Туликова О.В. 2012. Механизмы повышения энергоэффективности, Энергосбережение, (№ 4): 4-10;

17.Федеральный закон от 23.11.2009 № 261-Ф3 (ред. от 26.07.2019) «Об энергосбережении и о повышении энергетической эффективности, и о внесении изменений в отдельные законодательные акты Российской Федерации»;

18.Alessandra Celani de Macedo, Nicola Cantore. The impact of industrial energy efficiency on economic and social indicators URL:https://www.feem.it/m/publications_pages/ndl2020-001.pdf (дата обращения 25 февраля 2020);

19.Iñigo Bonilla-Camposab, Nerea Nieto. 2020. Energy efficiency optimisation in industrial processes: Integral decision support tool. Energy, Volume 191.

20.Huysmana S., Sala S. 2015. Toward a systematized framework for resource efficiency indicators. resources, conservation and recycling, (95): 68-76;

21.König W. 2020. Energy efficiency in industrial organizations. A cultural-institutional framework of decision making, energy research \& social science, volume 60 ;

\section{References}

1. Bashmakov I.A. 2014. Za schet chego snizhaetsya e`nergoemkost` VVP Rossii. E`nergosberezhenie, (№ 1): 12-18;

2. Bashmakov I.A., Bashhmakov V.I. 2012. Politika povy`sheniya e`nergoe`ffektivnosti Rossii, E`nergosberezhenie, (№ 4): 10-16;

3. Bashmakov I.A. 2018. Chto proisxodit s e`nergoemkost`yu VVP Rossii? E`kologicheskij vestnik Rossii, (№ 7):18-29;

4. Bashmakov I.A. 2016. E`nergopotreblenie regionov Rossii. O real’noj dinamike i o kachestve statistiki. E`nergosberezhenie, (№ 5):24-29;

5. Golovanova L.A., Moskovceva A.A. 2014. Faktory`i usloviya e`nergoe`ffektivnosti v promy`shlennosti. Vestnik TOGU, № 3(34): 137-146;

6. Gosudarstvenny`j doklad o sostoyanii e`nergosberezheniya i povy`shenii e`nergeticheskoj e`ffektivnosti v Rossijskoj Federacii URL:https://www.economy.gov.ru/material/file/d81b29821 e3d3f5a8929c84d808de81d/energyefficiency2019.pdf (data obrashheniya 25 fevralya 2020);

7. Dzyuba A.P., Solov`eva I.A. 2018. Kratkosrochnoe prognozirovanie parametrov potrebleniya prirodnogo gaza kak e`lement cenozavisimogo upravleniya e`nergozatratami na promy`shlenny`x predpriyatiyax. Vestnik VolGU. Seriya 3, E`konomika. E`kologiya. T. 20 (№ 1):78 - 90;

8. Ishkov A.G., Cybul`skij P.G., Py`stina N.B. i dr. 2013. Strategiya formirovaniya metodov upravleniya e`nergosberezheniem v OAO «Gazprom». Vesti gazovoj nauki: Oxrana okruzhayushhej sredy`, e’nergosberezhenie i oxrana truda $v$ neftegazovom komplekse: innovacii, texnologii, perspektivy’, № 2 (13): 14-20;

9. Koksharov V.A. 2016. Sistematizaciya faktorov e`nergoe`ffektivnosti promy`shlennogo predpriyatiya. Vestnik Permskogo universiteta. Seriya: e`konomika, 1(28): 147-156;

10. Kirshina I.A., Fedorova S.E. Sistematizaciya faktorov energoeffektivnosti potrebleniya prirodnogo gaza promyshlennymi predpriyatiyami. 2020. Problemy ekonomiki i upravleniya neftegazovym kompleksom, № 4(184): (str. 77 79);

11. Lebedev Yu.A., Letyagina E.N. 2014. Regressionny`j analiz e`nergopotrebleniya v promy`shlenny`x regionax. Vestnik Nizhegorodskogo universiteta im. N.I. Lobachevskogo. Seriya: social’ny`e nauki, № 3(35): 29-32;

12. Marchenko E.M., Belova T.D. Analiz faktorov, vliyayushhix na e`nergoe'ffektivnost' regiona: upravlencheskij aspekt. URL: http://vestnik.uapa.ru/ru/issue/2015/04/15/ (data obrashheniya 12 yanvarya 2019);

13. Moruleva L.A. 2015. Analiz faktorov, okazy`vayushhij vliyanie na e`nergoe`ffektivnost` e`konomiki. Mezhdunarodny`j nauchno-issledovatel`skij zhurnal, 6-3 (37): 75-77;

14. Pokazateli e`nergoe`ffektivnosti: osnovy` formirovaniya politiki. URL:https://altenergiya.ru/ wpcontent/uploads/books/common/pokazateli-energoeffektivnosti.pdf (data obrashheniya 12.01.2019);

15. Prognoz razvitiya e’nergetiki mira i Rossii do 2040 goda. URL:https://www.eriras.ru/ files/prognoz-2040.pdf (data obrashheniya 25 fevralya 2020); 
16. Tulikov A.V., Tulikova O.V. 2012. Mexanizmy` povy`sheniya e`nergoe`ffektivnosti, E’nergosberezhenie, (№ 4): 4-10;

17. Federal `ny’j zakon ot 23.11.2009 № 261-FZ (red. ot 26.07.2019) «Ob e`nergosberezhenii i o povy`shenii e`nergeticheskoj e`ffektivnosti, i o vnesenii izmenenij v otdel`ny`e zakonodatel`ny`e akty` Rossijskoj Federacii»;

18. Alessandra Celani de Macedo, Nicola Cantore. The impact of industrial energy efficiency on economic and social indicators URL:https://www.feem.it/m/publications_pages/ndl2020-001.pdf (дата обращения 25 февраля 2020);

19. Iñigo Bonilla-Camposab, Nerea Nieto. 2020. Energy efficiency optimisation in industrial processes: Integral decision support tool. Energy, Volume 191.

20. Huysmana S., Sala S. 2015. Toward a systematized framework for resource efficiency indicators. resources, conservation and recycling, (95): 68-76;

21. König W. 2020. Energy efficiency in industrial organizations. A cultural-institutional framework of decision making, energy research \& social science, volume 60;

\section{Ссылка для цитирования статьи For citation}

Киршина И.А. 2020. Выявление и классификация показателей энергетической эффективности предприятия как основа рационального расходования топливно-энергетических ресурсов. Экономика. Информатика. 47 (2): 308-316. DOI: 10.18413/2687-0932-2020-47-2-308-316.

Kirshina I.A. 2020. Identification and classification of indicators of energy efficiency of the enterprise as the basis of rational consumption of fuel and energy resources. Economics. Information technologies. 47 (2): 308-316 (in Russian). DOI: 10.18413/2687-0932-2020-47-2-308-316. 